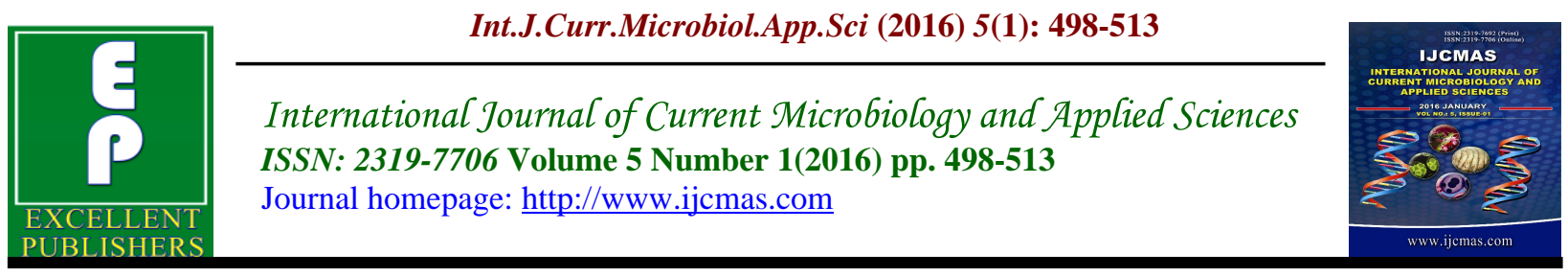

Original Research Article

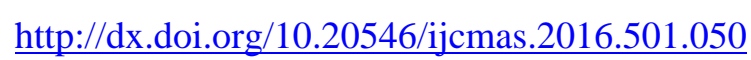

\title{
Synthesis of a Novel Unsaturated Polyolefin Intermediates, Aldehyde and Fatty Acid
}

\author{
Hussein Habeeb Mustafa* \\ Department of Basic Sciences, Faculty of Dentistry, University of Kirkuk, Kirkuk, Iraq \\ *Corresponding author
}

A B S T R A C T

Keywords

Wittig reaction,

Skip-conjugated

Alkenes,

Pheromone

Article Info

Accepted:

22 December 2015

Available Online:

10 January 2016

Novel unsaturated compounds with the required skip-conjugated (Z,Z)double bonds configuration are synthesized through a coupling of aldehydes with phosphonium salt through a series of Wittig reactions as a main step. The products were diagnosed by using NMR spectrum, infrared (IR) and mass spectrometer techniques. It is concluded that these products could widely be used as a fatty acid and a useful intermediates in the synthesis of pheromones instead of insecticides, and several chemical reactions.

\section{Introduction}

Many natural biologically active products bear skipped alkene units with all $\mathrm{Z}$ configuration which are known as polyunsaturated compound like polyunsaturated fatty acid. ${ }^{1}$ The importance of polyunsaturated fatty acids in diet and human health is well documented. Fatty acids have several usages which retain them important. Some cellular functions do use them as energy storage molecules and as hydrophobic core of membranes. They also maintain a favourable effect on human diseases such as arthritis, ${ }^{2}$ renal disorders, ${ }^{3}$ cancer, $^{4}$ and contribute into various signalling pathways.
Recently, fatty acid functional studies have been considered as an attractive model in several areas. All of the enzymes which produce omega- 6 and omega- 3 fatty acids are synthesized by the Caenorhabditis elegans 5,6 . Generally, polyunsaturated fatty acids molecules consist a group of Z-double bonds separated by $\mathrm{CH} 2$, 'skip-conjugated' or methylene-interrupted systems. This system is similar to many pheromonal system. Most of this type of polyunsaturated molecules have been prepared by controlled hydrogenation of a skip-conjugated polyacetylene, ${ }^{7,8}$ or isolated from the natural sources. Other references reported that the 
ability to use 6,6-di-alkoxy-Z-hex-3-en-1-al and a range of related systems, as homologating agents to synthesis same type of compounds using Wittig reactions. ${ }^{9-12}$ The bjectives of this study are to synthesize several useful intermediates which contain (5Z,7Z,8Z and 9Z) double bond formation. These products may easily be utilized in many fields to prepare some intermediates to implement in preparation of pheromones, polyunsaturated aldehydes and fatty acid compounds in high yields and low costs.

\section{Methodology}

\section{Experimental}

\section{General}

Chemicals used were obtained from commercial suppliers (Sigma, Aldrich, and Alfa Ayser) or prepared from them by the methods described. All reagents and solvents used were of reagent grade unless otherwise stated.

Silica gel (Merck 7736) and silica gel plates used for column chromatography and thin layer chromatography were obtained from Aldrich; separated components were detected using variously UV light, $\mathrm{I}_{2}$ and phosphomolybdic acid solution in IMS followed by charring. Anhydrous magnesium sulfate was used to dry organic solutions. Infra-red (IR) spectra were carried out on a Perkin-Elmer 1600 F.T.I.R. spectrometer as liquid films or $\mathrm{KBr}$ disc (solid).

NMR spectra were carried out on a Bruker AC250 or Advance 400 spectrometer. Mass spectra were recorded on Bruker Micro TOF using electron impact ionization or by direct insertion matrix-assisted laser desorption / ionisation-time of flight mass spectrometry (MALDI-TOF MS).
Synthesis of (3Z,6Z,9Z,12Z,15Z)octadeca-3,6,9,12,15-Pentaenedial (2)

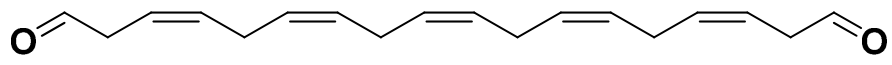

Formic acid $80 \%{ }^{12,13}$ (6 mL) was added dropwise to a stirred solution of (3Z,6Z,9Z,12Z,15Z)-1,1,18,18tetramethoxyoctadeca-3,6,9,12,15pentaene $^{14}(0.20 \mathrm{~g}, 0.60 \mathrm{mmol})$ in dioxane $(6$ $\mathrm{mL}$ ) at room temperature. The mixture was stirred at room temperature for $1.5 \mathrm{hrs}$, followed by the addition of water $(10 \mathrm{~mL})$. The product was extracted with dichloromethane $(3 \mathrm{x} 25 \mathrm{~mL})$ and the combined organic layers were washed with sat.aq. $\mathrm{NaHCO}_{3}(15 \mathrm{~mL})$, brine $(15 \mathrm{~mL})$ and dried over $\mathrm{MgSO}_{4}$ then evaporated to give a crude product which was purified by column chromatography on silica eluting with petrol:ethyl acetate $(5: 1)$ to give (3Z,6Z,9Z,12Z,15Z)-octadeca-3,6,9,12,15pentaenedial (2) ( $0.135 \mathrm{~g}, 90 \%)$.

Synthesis of $(6 \mathrm{Z}, 9 \mathrm{Z}, 12 \mathrm{Z}, 15 \mathrm{Z}, 18 \mathrm{Z}$, 21Z,24Z)-Triaconta-6,9,12,15,18,21,24Heptaene (4)

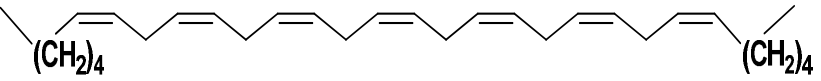

Sodium bis(trimethylsilyl)amide (4 ml) was added to a stirred solution of hexyltriphenylphosphonium bromide (3)(0.5 $\mathrm{g}, 1.2 \mathrm{mmol}$ ) at $-78^{\circ} \mathrm{C}$.

The reaction mixture was gradually warmed to room temperature then cooled down again to $-78{ }^{\circ} \mathrm{C}$ and $(3 \mathrm{Z}, 6 \mathrm{Z}, 9 \mathrm{Z}, 12 \mathrm{Z}, 15 \mathrm{Z})-$ octadeca-3,6,9,12,15-pentaenedial (2) (0.27 $\mathrm{g}, 1 \mathrm{mmol})$ was added. The reaction was quenched as above to give (6Z,9Z,12Z,15Z,18Z,21Z,24Z)-triaconta$6,9,12,15,18,21,24$-heptaene $(4)(0.3 \mathrm{~g}, 75$ $\%)$. 
Synthesis of $(3 Z, 6 Z, 9 Z, 12 Z, 15 Z, 18 Z, 21 Z$, 24Z)-Heptacosa-3,6,9,12,15,18,21,24Octaenal (6)

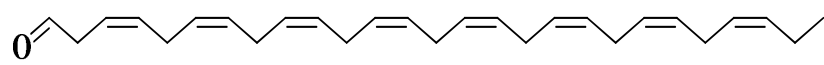

Using the same procedure as above formic acid $80 \%(3 \mathrm{~mL})$ was added dropwise to a stirred solution (3Z,6Z,9Z,12Z, 15Z,18Z, 21Z,24Z)-1,1-dimethoxyheptacosa-3,6,9, 12,15,18,21,24-octaene (5) $(0.2 \quad \mathrm{~g}, \quad 0.47$ $\mathrm{mmol})$ in dioxane $(3 \mathrm{~mL})$ at room temperature. The mixture was stirred at room temperature for $1.5 \mathrm{hrs}$, followed by the addition of water $(5 \mathrm{~mL})$. The product was extracted with dichloromethane $(3 \times 20$ $\mathrm{mL}$ ) and the combined organic layers were washed with sat.aq. $\mathrm{NaHCO}_{3}(10 \mathrm{~mL})$, brine $(10 \mathrm{~mL})$ and dried over MgSO4then evaporated to give a crude product which was purified by column chromatography on silica eluting with petrol:ethyl acetate $(5: 1)$ to give (3Z,6Z,9Z,12Z,15Z,18Z,21Z,24Z)heptacosa-3,6,9,12,15,18,21,24-octaenal (6) $(0.13 \mathrm{~g}, 76 \%)$.

Synthesis of $(7 \mathrm{Z}, 10 \mathrm{Z}, 13 \mathrm{Z}, \quad 16 \mathrm{Z}, 19 \mathrm{Z}$, 22Z,25Z,28Z,31Z)-Tetratriaconta-7,10,13, $16,19,22,25,28,31$-Nonaenoic acid (9)

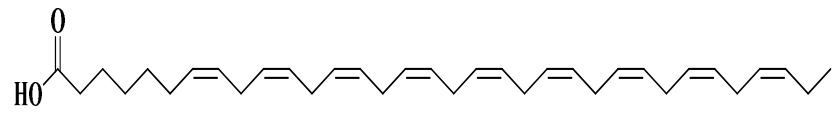

Sodium bis(trimethylsilyl)amide ( $3 \mathrm{ml})$ was added dropwise to a stirred slurry of (6carboxy-hexyl) triphenylphosphonium bromide (7)(0.5 g, $1.1 \mathrm{mmol})$ in dry THF $(20 \mathrm{~mL})-78{ }^{\circ} \mathrm{C}$, under nitrogen. The reaction mixture was allowed to reach room temperature and stirred for $30 \mathrm{~min}$, then cooled again to $-78{ }^{\circ} \mathrm{C}$, and $(3 \mathrm{Z}, 6 \mathrm{Z}, 9 \mathrm{Z}$, 12Z,15Z,18Z,21Z,24Z)-heptacosa-3,6,9, $12,15,18,21,24$-octaenal $\quad(6)(0.2 \quad \mathrm{~g}, \quad 0.8$ $\mathrm{mmol})$ in dry THF ( $3 \mathrm{~mL})$ was added. The mixture was stirred and allowed slowly to reach room temperature, then cooled to $0{ }^{\circ} \mathrm{C}$ and quenched with sat. aq. $\mathrm{NH}_{4} \mathrm{Cl}(15 \mathrm{~mL})$. The product was extracted with ethyl acetate $(3 \times 50 \mathrm{~mL})$. The combined organic layers were dried over $\mathrm{MgSO}_{4}$ and evaporated. The residue was purified by column chromatography on silica eluting with petrol to (7Z,10Z,13Z,16Z,19Z,22Z,25Z,28Z,31Z)tetratriaconta-7,10,13,16,19,22,25,28,31nonaenoic acid (9) (0.22 g, $84 \%)$.

Synthesis of $(3 Z, 6 Z, 9 Z, 12 Z, 15 Z, 18 Z, 21 Z$, 24Z, 27Z)- Pentatriaconta-3,6,9,12,15,18, 21,24,27-Nonaene (10)

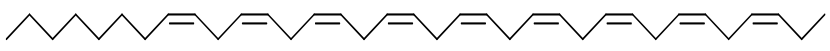

Using the same procedure as above, (3Z,6Z,9Z,12Z,15Z,18Z,21Z,24Z,27Z)pentatriaconta-3,6,9,12,15,18,21,24,27nonaene $(10)(0.27 \mathrm{~g}, 81 \%)$ was prepared by using octyltriphenylphosphonium bromide $\left(\begin{array}{llll}0.5 & \mathrm{~g}, & 1.1 & \mathrm{mmol}\end{array}\right), \quad$ sodium bis(trimethylsilyl)amide $(3 \mathrm{~mL})$ and $(3 \mathrm{Z}, 6 \mathrm{Z}$, 9Z,12Z,15Z,18Z,21Z,24Z)-heptacosa-3,6,9, $12,15,18,21,24$-octaenal $(0.27 \mathrm{~g}, 0.7 \mathrm{mmol})$ in THF $(15 \mathrm{~mL})$ under nitrogen. The reaction was worked up as before and the product was purified by column chromatography eluting with petrol : ethylacetate $(5: 2)$.

\section{Results and Discussion}

Out interest in the stereuselective cis-Wittig olefination has led to the proposal of a new strategy for the synthesis of polyunsaturated fatty acids which are featured by methyleneinterrupted cis double bonds. Our approach is based on the oxidative coupling of the ylid derived from the previously described.

It is known that the acetal which has been used to prepare pheromones containing Zalkenes.3,4,5 Continuous with what we had been prepared later we successfully to insert di-acetal in new chemical reactions to 
syntheses several novel polyunsaturated compounds like aldehyde, fatty acid and intermediates with skip-conjugated $(\mathrm{Z}, \mathrm{Z})$ double bonds.

In this step was the selective conversion of bis-acetal (1) to the corresponding dialdehyde, by deprotection of the di-acetal (3Z,6Z,9Z,12Z,15Z)-1,1,18,18-tetramethoxyocta-deca-3,6,9,12,15-pentaene with $80 \%$ formic acid in dioxane which led to the corresponding unstable aldehyde (3Z,6Z,9Z,12Z,15Z)-octadeca-3,6,9,12,15pentaenedial (2) in $90 \%$ yield.

The ${ }^{1} \mathrm{H}$ NMR spectrum of aldehyde (2) showed a triplet at $\delta 9.69(2 \mathrm{H}, \mathrm{J} 1.8 \mathrm{~Hz})$ for the aldehyde protons. The olefinic protons were observed as a four proton multiplet next to the aldehyde groups between 5.7 and 5.5 and eight proton multiplet at $\delta 5.4$ for the other alkenes protons, and the methylene protons next to the aldehyde as a doublet at $\delta 3.23(4 \mathrm{H}, \mathrm{J} 7.1 \mathrm{~Hz})$. The methylene protons between and next to the five double bonds appeared as a broad multiplet at $\delta$ $2.83(8 \mathrm{H})$.

The ${ }^{13} \mathrm{C}$ NMR showed signals at $\delta 199.3$ for the carbonyl carbon of the aldehyde, at $\delta$ 42.4 for the carbon next to the aldehyde carbon, and showed the required ten alkene carbons between $\delta$ 133.1- 118.6. The signals occurred at $\delta 25.9$ and 25.6 for the methylene groups between alkene double bonds. The infrared spectrum confirmed the success of the deprotection, showing an absorbance at $1731 \mathrm{~cm}^{-1}$ corresponding to the aldehyde carbonyl group. This pentaenedial (2) was used directly in the next step, a Wittig reaction with several alkyltriphenylphosphonium bromide (3) and base to give several products with heptaene group.

\section{The Wittig Reaction}

The Wittig reaction is the key step in this strategy. This, in general, is a reaction between an aldehyde or a ketone (A) with a triphenyl phosphonium ylide (B), forming an alkene in the cis or trans configuration $\mathrm{A}$ high selectivity for an (E) or (Z) alkene can be achieved, depending on the conditions employed in the reaction or the substance of the starting material.

The Wittig reaction in general gives product (C) in the Z-configuration unless the ylid (B) is stabilised by an electron withdrawing substituent. It has been reported that the stereochemistry of the product is dependent on the oxaphosphetane elimination step. The initial step in the Wittig reaction treats the phosphonium salt with a base to form an ylid (D). The stability of that ylide leads to either the $(Z)$ or $(E)$ configuration of the alkenes $(\mathrm{Z})$ and $(\mathrm{E})$; a non-stabilised ylide (D) leads to the $(\mathrm{Z})$ isomer, while a more stable gives the $(\mathrm{E})$ isomer. ${ }^{15}$ The stability of the ylide (D) is due to the R-group in the phosphonium salt; this contains an electron withdrawing group and makes the ylide (D) more stable. ${ }^{16,17}$

Other conditions can affect the stereochemistry of the product of a Wittig reaction. ${ }^{18}$ The solvent used in the reaction can affect the stereochemistry of the product. Reitz et al. demonstrated the effect of the solvent and in general concluded that THF, DME, ether and tert-butyl methyl ether are the solvents of choice for higher yields of $(\mathrm{Z})$ isomers, while alcohols and DMSO should be avoided. ${ }^{19}$ The base used to generate the anion from the phosphonium salt can affect the $(\mathrm{Z} / \mathrm{E})$ ratio of the product. Potassium bases give a higher ratio of cis isomers to trans isomers, while sodium bases are less selective and lithium bases give a higher ratio of trans to cis isomers (Fig. 5). ${ }^{20}$

In the current study, reaction of the bromide with triphenylphosphine to obtain Wittig 
salts with different chain lengths (3) $(n=4,5$ and 6). This can readily be used as an intermediate to prepare a range of molecules containing seven skip-conjugated Z-alkenes (4).

The Wittig coupling was used between triphenyl phosphonium salt (3) and pentaene aldehyde (3Z,6Z,9Z,12Z,15Z)-octadeca-3,6, 9,12,15-pentaenedial (2), the reaction had been in dry THF at low temperature, in the presence of sodium bis(trimethylsilyl)amide as a base, to give compound (4), the structures of which were confirmed by their mass spectra, IR and the NMR spectra.

The ${ }^{1} \mathrm{H}$ NMR spectra of (4) showed disappearing aldehydes groups signals, and two chine with several methylene groups $(n=4,5$ and 6) were appeared as mention in a figure above. For example, NMR spectrum of the compound (4) when $n=4$ showed multiplets signal between $\delta 5.4$ and $\delta 5.3$ which corresponded to sets of overlapping double bonds, The two sets of methylene protons situated between the double bonds appeared as a multiplet at $\delta$ 2.8. The methylene protons next to the double bond appear as a signal at $\delta 2.0$, while the chain methylene groups appear as a signal at $\delta 1.2$, and the signal at $\delta 0.9$ were for the two terminal methyl groups. The ${ }^{13} \mathrm{C}$ NMR spectra showed the required number of resonances, including seven alkene protons signals between $\delta 130$ and $\delta 127 \mathrm{ppm}$. The terminal methyl carbon signals were observed at $\delta 14.06$ and $\delta 14.1 \mathrm{ppm}$. No trace of trans or conjugated compounds could be found by ${ }^{13} \mathrm{C}$ NMR and ${ }^{1} \mathrm{H}$ NMR analysis.

In the second line we successfully entered the $(3 Z, 6 Z, 9 Z, 12 Z, 15 Z, 18 Z, 21 Z, 24 Z)-1,1-$ dimethoxyheptacosa-3,6,9,12,15,18,21,24octaene (5), which we prepared in our Ph.D. study to synthesis a novel very long polyunsaturated aldehyde (6), fatty acid (9) and several intermediate with eight and nine alkene double bonds (10) respectively.

The acetate (5) was treated with formic acid $80 \%$ in dioxane to deprotect the acetal group, and produce the unstable aldehyde give (3Z,6Z,9Z,12Z,15Z,18Z,21Z,24Z)heptacosa-3,6,9,12,15,18,21,24-octaenal (6), in $76 \%$ yield.

The proton NMR spectrum of this displayed the aldehyde proton as a triplet at $\delta 9.68(\mathrm{~J}$ $1.8 \mathrm{~Hz}$ ), and the sixteen alkene protons as a multiplet between $\delta 5.74$ and 5.29, reflecting the presence of eight double bonds within the molecule. A broad doublet at $\delta 3.23$ refer to the methylene protons next to the aldehyde function group, a multiplet occurred between $\delta 2.89$ to 2.79 for the methylene protons between the eight double bonds. The methylene protons next to the terminal alkyl group appeared at $\delta 2.08$ while the terminal methyl group appeared as a triplet at $\delta 0.98$.

By coupling the phosphonium salt (7) and aldehyde (6) in a Wittig reaction using sodium bis(trimethylsilyl)amide, (7Z,10Z,13Z,16Z,19Z,22Z,25Z,28Z,31Z)tetratriaconta-7,10,13,16,19,22,25,28,31nonaenoic acid (9) was obtained in a $84 \%$ yield, while the coupling of same aldehyde (6) with the phosphonium salt (8) lead to (3Z,6Z,9Z,12Z,15Z,18Z,21Z,24Z,27Z)pentatriaconta-3,6,9,12,15,18,21,24,27nonaene (10) in a $81 \%$ yield.

The ${ }^{1} \mathrm{H}$ NMR spectrum of the nonaenoic acid (9) showed a multiplet between $\delta 5.48$ and 5.28 for the eighteen alkene protons, reflecting the presence of nine double bonds within the molecule. A multiplet occurred at $\delta 2.91-2.78$ for the methylene protons between the nine double bonds. The alkyl chain signals between alkene and carboxylic 
acid group appeared at $\delta 2.36,2.18,1.67$ and 1.43 respectively. The methylene protons next to the terminal alkyl group appeared at $\delta 2.08$ while the terminal methyl group appeared as a triplet at $\delta 0.98$. However, the aldehyde signal had disappeared while a new signal appeared at $\delta$ 11.18, corresponding to the carboxylic acid group proton.

Table.1 Mass, NMR and IR Analysis of Compound (3Z,6Z,9Z,12Z,15Z)-

Octadeca-3,6,9,12,15-Pentaenedial

\begin{tabular}{ll}
\hline Mass & 272.177 \\
$\delta \mathrm{H}(500 \mathrm{MHz})$ & $\begin{array}{l}9.69(2 \mathrm{H}, \mathrm{t}, J=1.8 \mathrm{~Hz}), 5.79-5.50(4 \mathrm{H}, \mathrm{m}), 5.50-5.26(6 \mathrm{H}, \mathrm{m}), 3.23 \\
(4 \mathrm{H}, \mathrm{d}, J=7.1 \mathrm{~Hz}), 2.83(8 \mathrm{H}, \mathrm{t}, J=7.1 \mathrm{~Hz}) .\end{array}$ \\
& $\begin{array}{l}199.31,133.10,128.72,128.07,127.21,118.71,42.49,25.97,25.66 . \\
\delta^{13} \mathrm{C}(101 \mathrm{MHz})\end{array}$ \\
$v_{\max } / \mathrm{cm}^{-1}$ & $2927,2861,1731,1609,1493,1451,1402,727$. \\
\hline
\end{tabular}

Table.2 Mass, NMR and IR Analysis of Compound to (6Z,9Z,12Z,15Z,18Z,21Z,24Z)-

Triaconta-6,9,12,15,18,21,24-Heptaene

\begin{tabular}{ll}
\hline Mass & 408.37 \\
$\delta \mathrm{H}(500 \mathrm{MHz})$ & $5.45-5.30(14 \mathrm{H}, \mathrm{br}, \mathrm{m}), 2.91-2.78(12 \mathrm{H}, \mathrm{br}, \mathrm{m}), 2.05(4 \mathrm{H}, \mathrm{m}), 1.42-$ \\
& $1.23(12 \mathrm{H}, \mathrm{m}), 0.90(6 \mathrm{H}, \mathrm{t}, \mathrm{J}=6.8 \mathrm{~Hz})$. \\
$\delta^{13} \mathrm{C}(101 \mathrm{MHz})$ & $130.49,128.59,128.28,128.18,128.09,127.85,127.53,31.52,29.32$, \\
& $27.22,25.64,22.57,14.06$. \\
& $2926,1744,1655,1493,1456,1363,1237,1036,824,721 \mathrm{~cm}^{-1}$. \\
\hline
\end{tabular}

Table.3 Mass, NMR and IR Analysis of Compound (3Z,6Z,9Z,12Z,15Z,18Z,21Z,24Z)Heptacosa-3,6,9,12,15,18,21,24-Octaenal (6)

\begin{tabular}{ll}
\hline Mass & 378.29 \\
$\delta \mathrm{H}(500 \mathrm{MHz})$ & $9.68(1 \mathrm{H}, \mathrm{t}, \mathrm{J} 1.8), 5.74-5.65(2 \mathrm{H}, \mathrm{m}), 5.64-5.57(2 \mathrm{H}, \mathrm{m}), 5.45-5.29$ \\
& $(12 \mathrm{H}, \mathrm{m}), 3.23(2 \mathrm{H}, \mathrm{br} \mathrm{d}, \mathrm{J} 7.1), 2.89-2.79(14 \mathrm{H}, \mathrm{br} \mathrm{m}), 2.11-2.04(2 \mathrm{H}$, \\
& br m), 0.98 (3H, t, J 7.5). \\
& $199.32,133.12,132.05,128.82,128.36,128.26,128.07,127.89,127.14$, \\
$\delta^{13} \mathrm{C}(101 \mathrm{MHz})$ & $118.69,42.49,25.97,25.65,25.53,20.55,14.26$. \\
& $2925,2860,1733,1609,1558,1494,1055,723$. \\
$v_{\max } / \mathrm{cm}^{-1}$ &
\end{tabular}


Table.4 Mass, NMR and IR Analysis of Compound (7Z,10Z,13Z,16Z,19Z,22Z,25Z,28Z,31Z)Tetratriaconta-7,10,13,16,19,22,25,28,31-Nonaenoic acid (9)

$\begin{array}{ll}\text { Mass } & 490.38 \\ & 11.18(1 \mathrm{H}, \mathrm{m}), 5.48-5.28(18 \mathrm{H}, \mathrm{m}), 2.91-2.78(16 \mathrm{H}, \mathrm{m}), 2.41-2.32 \\ \delta \mathrm{H}(500 \mathrm{MHz}) & (2 \mathrm{H}, \mathrm{m}), 2.18(2 \mathrm{H}, \mathrm{m}), 2.15-2.02(2 \mathrm{H}, \mathrm{m}), 1.67(2 \mathrm{H}, \mathrm{dt}, \mathrm{J}=15.3,7.5 \\ & \mathrm{Hz}), 1.43(4 \mathrm{H}, \mathrm{dt}, \mathrm{J}=14.8,7.5 \mathrm{~Hz}), 0.98(3 \mathrm{H}, \mathrm{t}, \mathrm{J}=7.5) . \\ \delta^{13} \mathrm{C}(101 \mathrm{MHz}) & 179.5,132.0,129.5,128.5,128.3,128.24,128.21,128.1,128.0,128.0, \\ & 127.8,127.0,33.8,28.9,26.8,25.6,25.5,24.2,20.5,14.2 . \\ v_{\max } / \mathrm{cm}^{-1} & 3444,3013,2962,2930,2860,1709,1658,1609,1493,724 .\end{array}$

Table.5 Mass, NMR and IR Analysis of Compound (3Z,6Z,9Z,12Z,15Z,18Z,21Z,24Z,27Z)Pentatriaconta-3,6,9,12,15,18,21,24,27-Nonaene (10)

$\begin{array}{ll}\text { Mass } & 474.42 \\ & 5.36(18 \mathrm{H}, \mathrm{m}), 2.82(16 \mathrm{H}, \mathrm{br} \text { pent., J 5.28), 2.0 }(2 \mathrm{H}, \mathrm{m}), 2.18(2 \mathrm{H}, \mathrm{br} \\ \delta \mathrm{H}(500 \mathrm{MHz}) & \text { sexset, J } 7.48 \mathrm{~Hz}), 1.31(10 \mathrm{H}, \mathrm{m}), 1.08(3 \mathrm{H}, \mathrm{t}, \mathrm{J} 7.56 \mathrm{~Hz}), 0.90(3 \mathrm{H}, \mathrm{t}, \mathrm{J} \\ & 6.56 \mathrm{~Hz}) . \\ \delta^{13} \mathrm{C}(101 \mathrm{MHz}) & 132.0,130.4,128.5,128.4,127.98,127.9,127.5,127.0,31.8,29.6,29.3, \\ & 29.2,27.2,25.7,25.6,25.5,22.6,20.5,14.2,14.1 . \\ & 2926,2859,1750,1609,1493,724 .\end{array}$

Fig.1 First Line of the Work

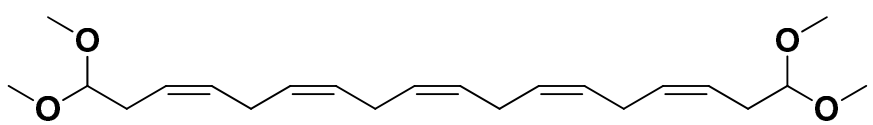

(1)

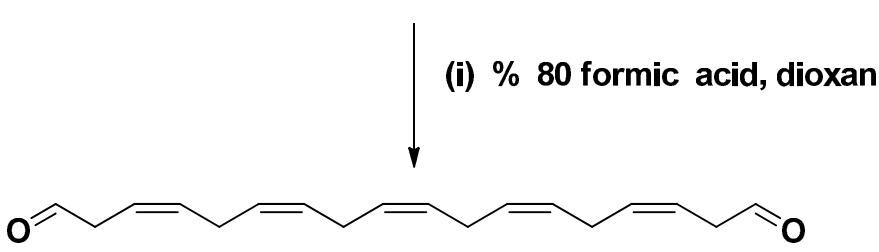

(2)

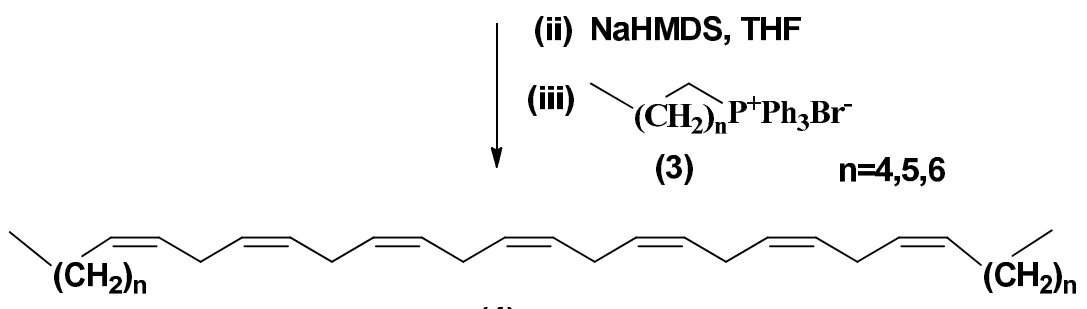

(4) 
Fig.2 Second Line of the Work

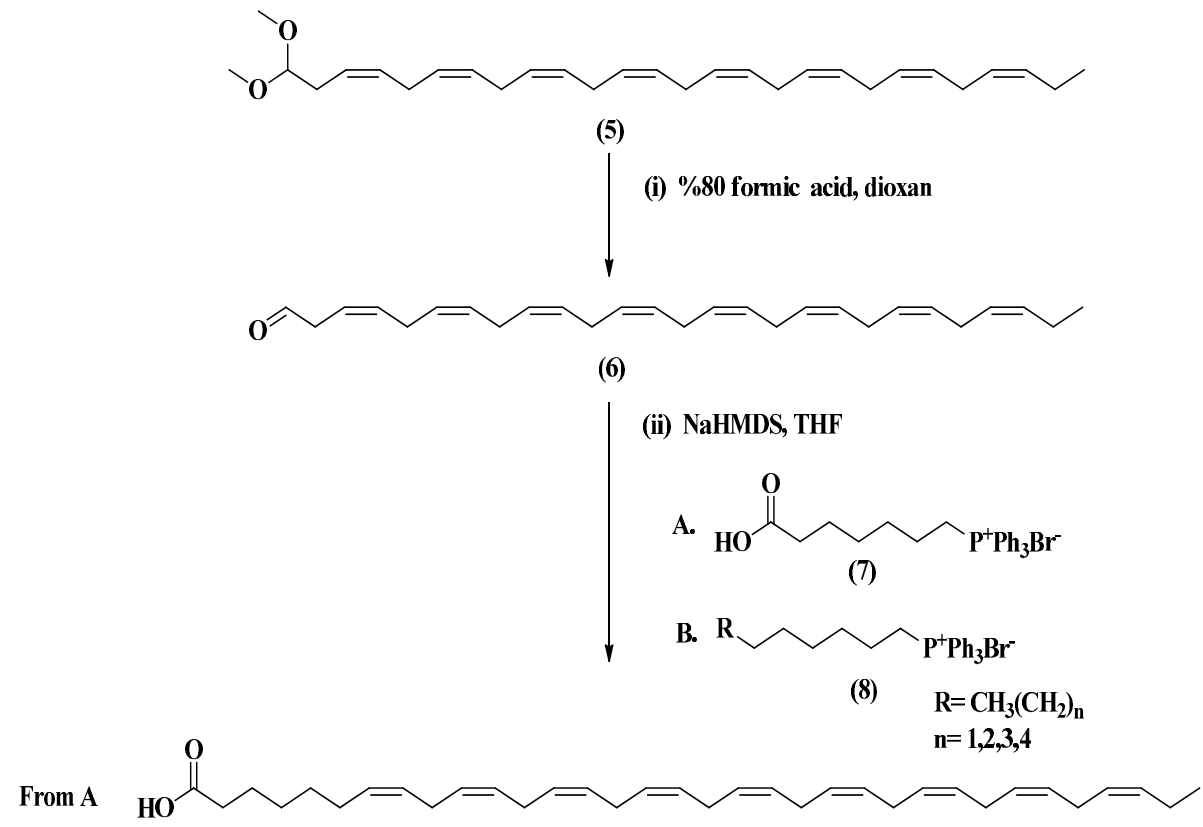

(9)

From B

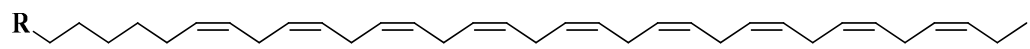

(10)

Fig.3 Preparation of (3Z,6Z,9Z,12Z,15Z)-Octadeca-3,6,9,12,15-Pentaenedial (2)

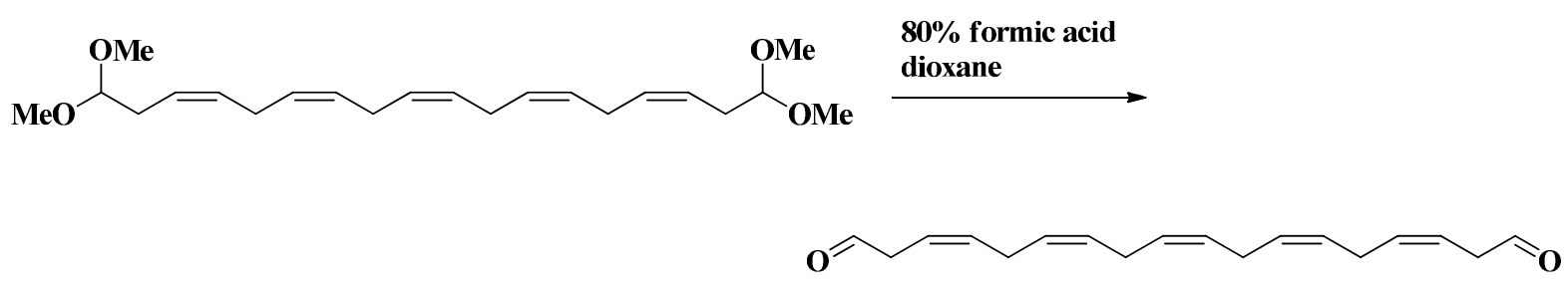

Fig.4 General Scheme of the Wittig Reaction

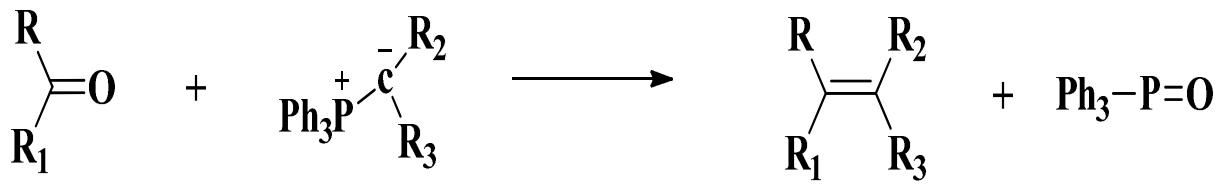

(A)

(B)

(C)

$\mathrm{R}, \mathrm{R}_{1}, \mathrm{R}_{2}$ and $\mathrm{R}_{3}=$ alkyl or $\mathrm{H}$ 
Fig.5 Forming Cis in the Wittig Reaction

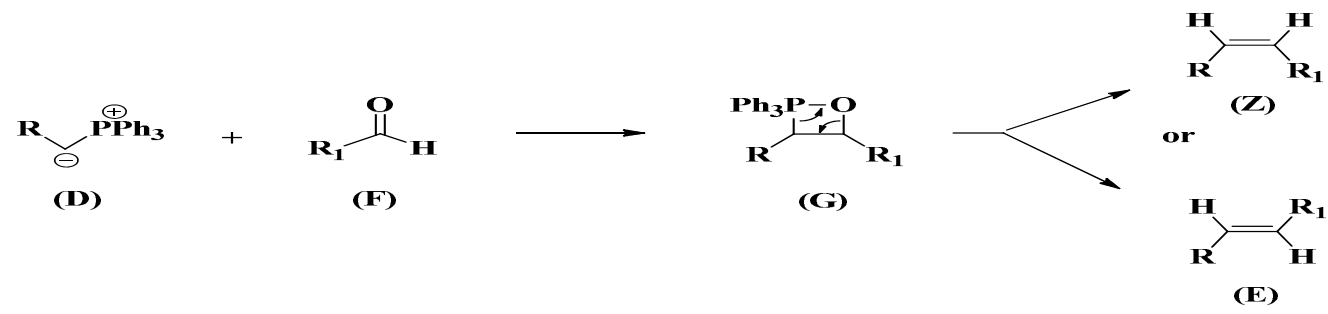

Fig.6 Preparation of (6Z,9Z,12Z,15Z,18Z,21Z,24Z)-Triaconta-6,9,12,15,18,21,24-Heptaene (4)

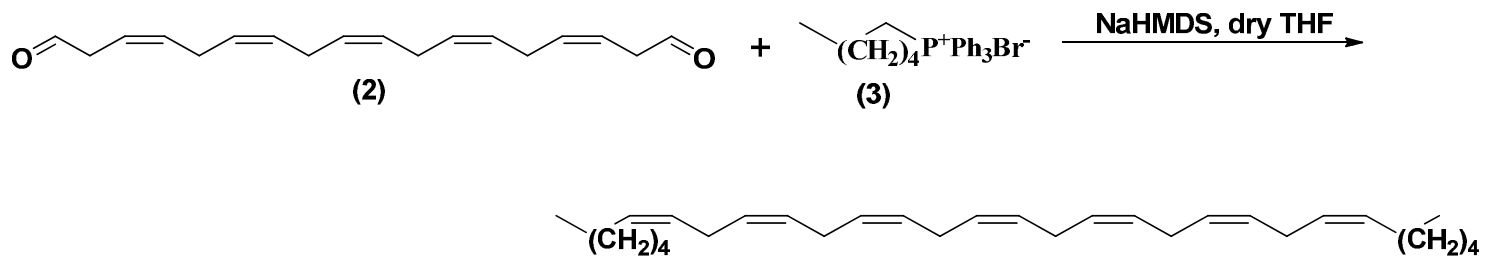

(4)

Fig.7 Preparation of (3Z,6Z,9Z,12Z,15Z,18Z,21Z,24Z)-Heptacosa-3,6,9,12,15,18,21,24Octaenal (6)

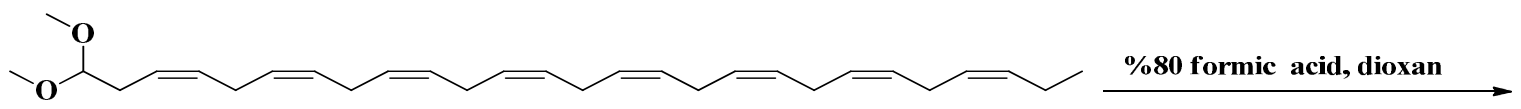

(5)

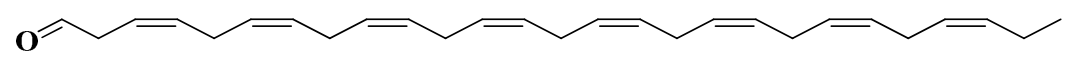

(6)

Fig.8.Preparation of Compound 9 and Compound 10

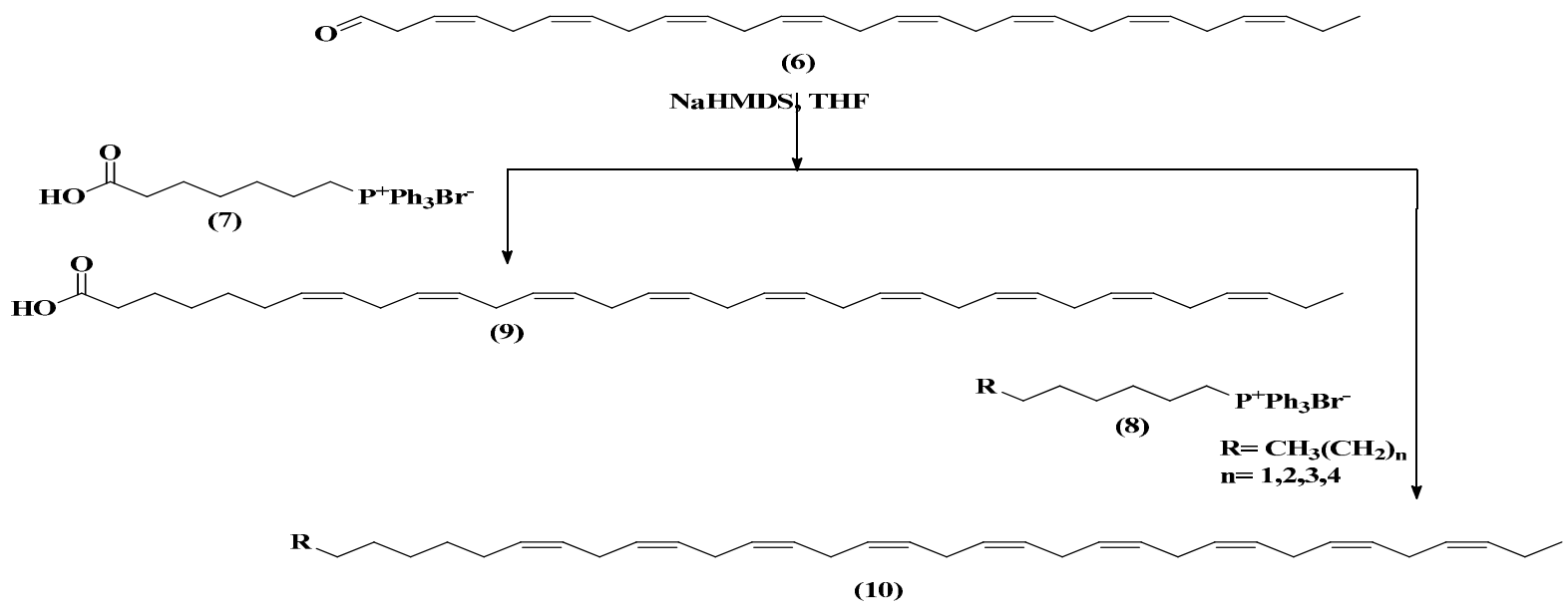




\section{Supplementary NMR Information}
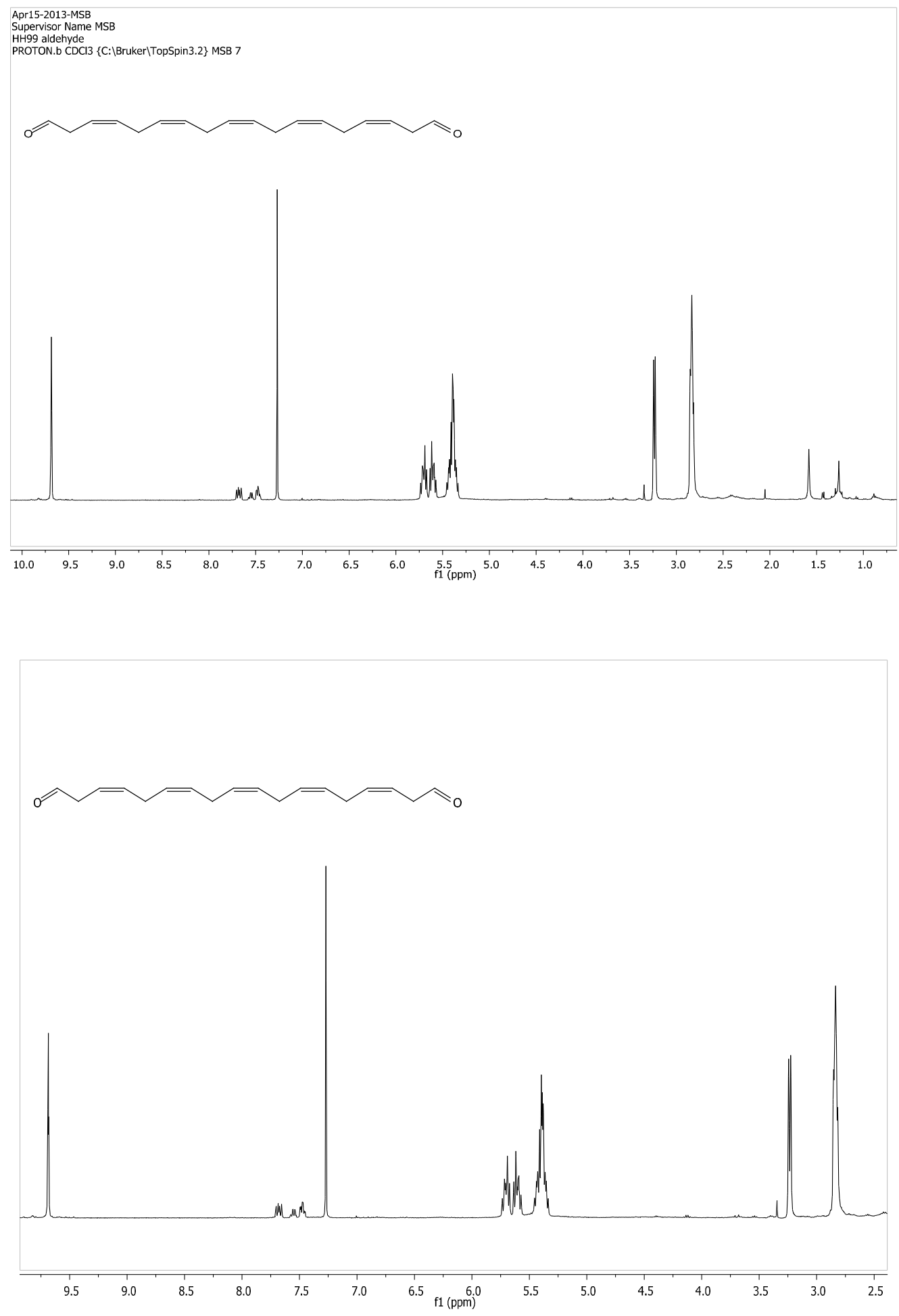

${ }^{1} \mathrm{H}$ NMR of compound (2) in $\mathrm{CDCl}_{3}$ 
Int.J.Curr.Microbiol.App.Sci (2016) 5(1): 498-513
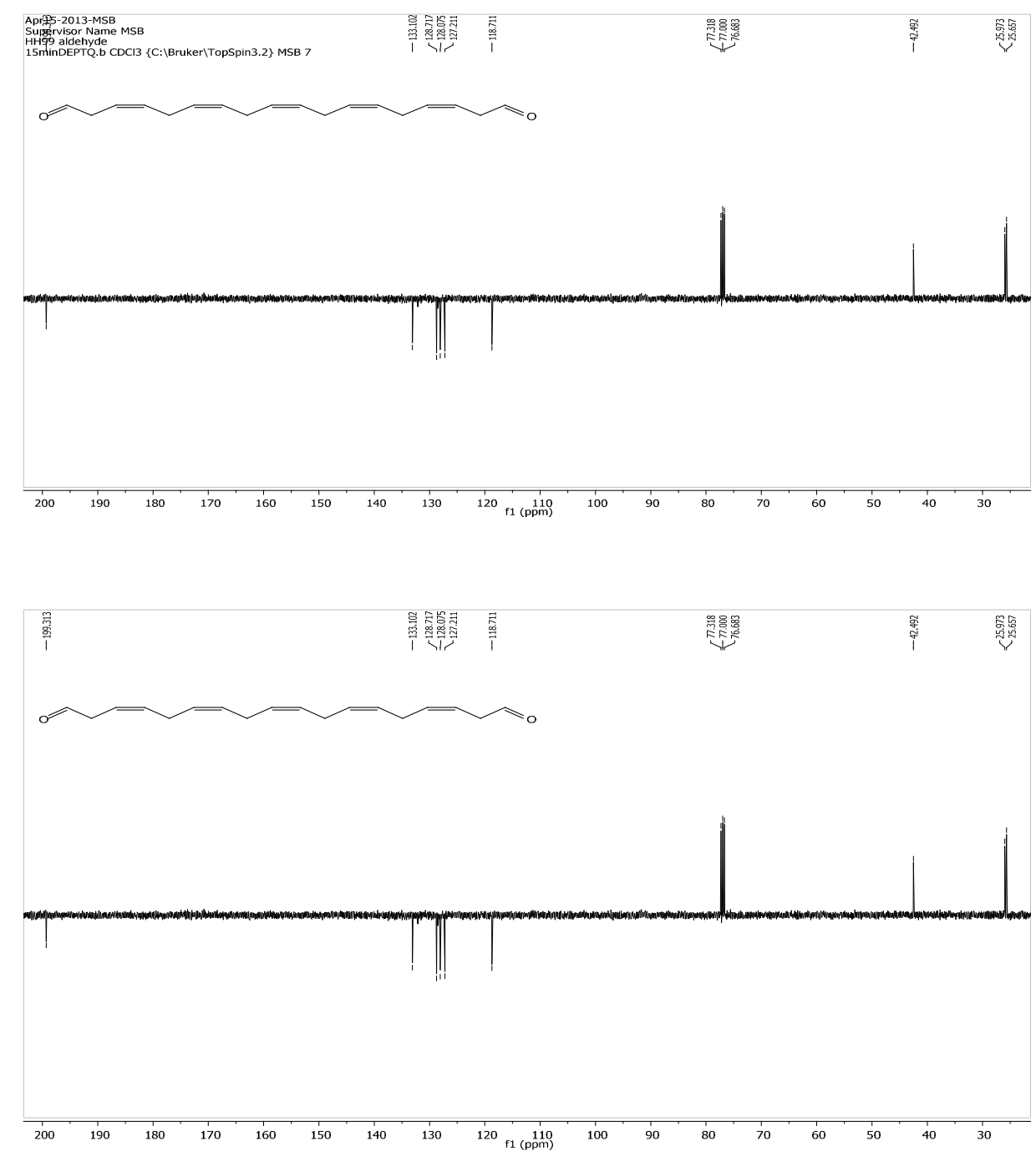

Dept-CNMR of compound (2) $\mathrm{CDCl}_{3}$

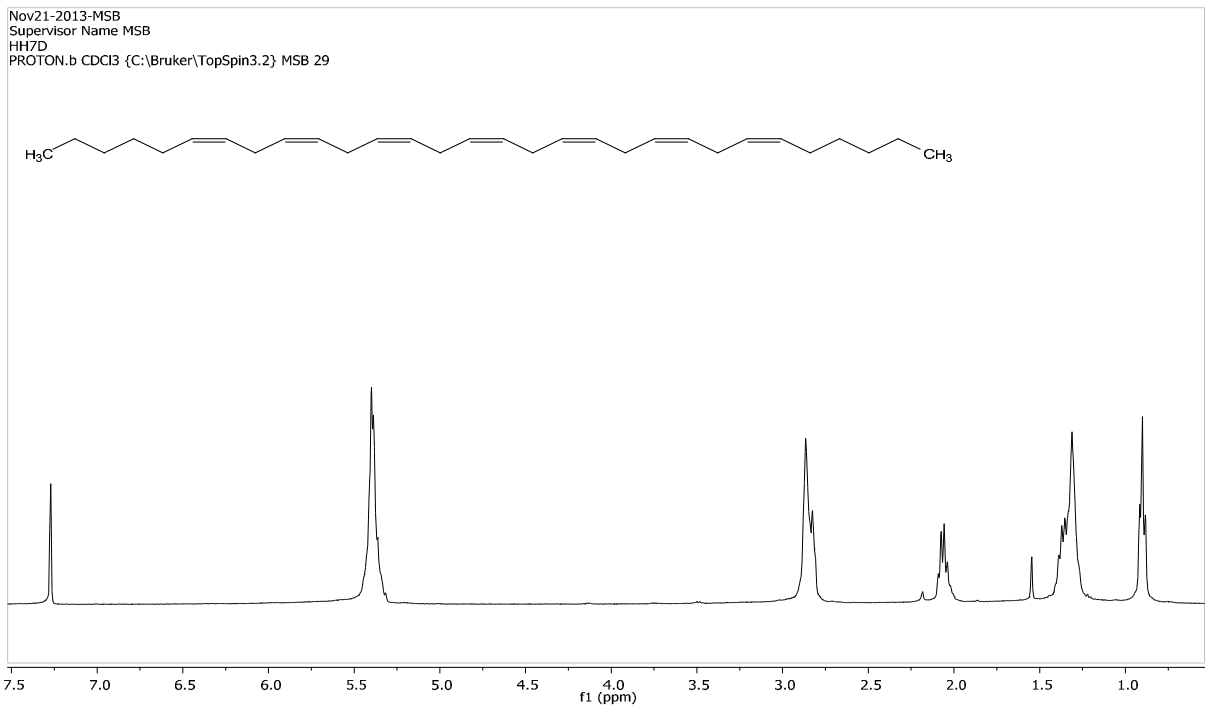


Int.J.Curr.Microbiol.App.Sci (2016) 5(1): 498-513

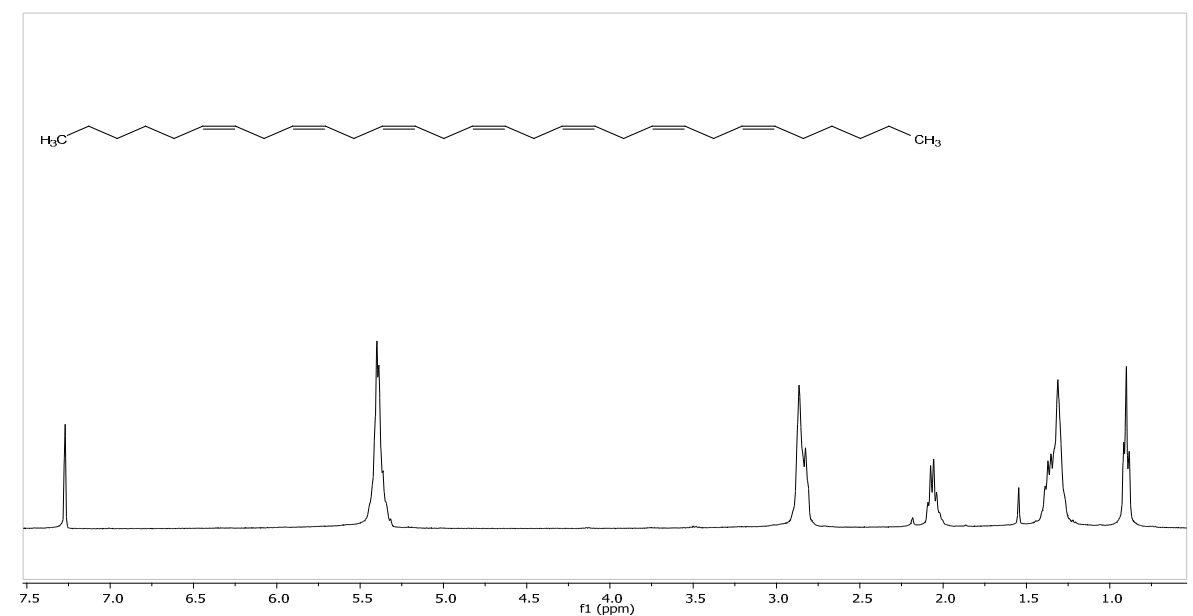

${ }^{1} \mathrm{H}$ NMR of compound (4) in $\mathrm{CDCl}_{3}$
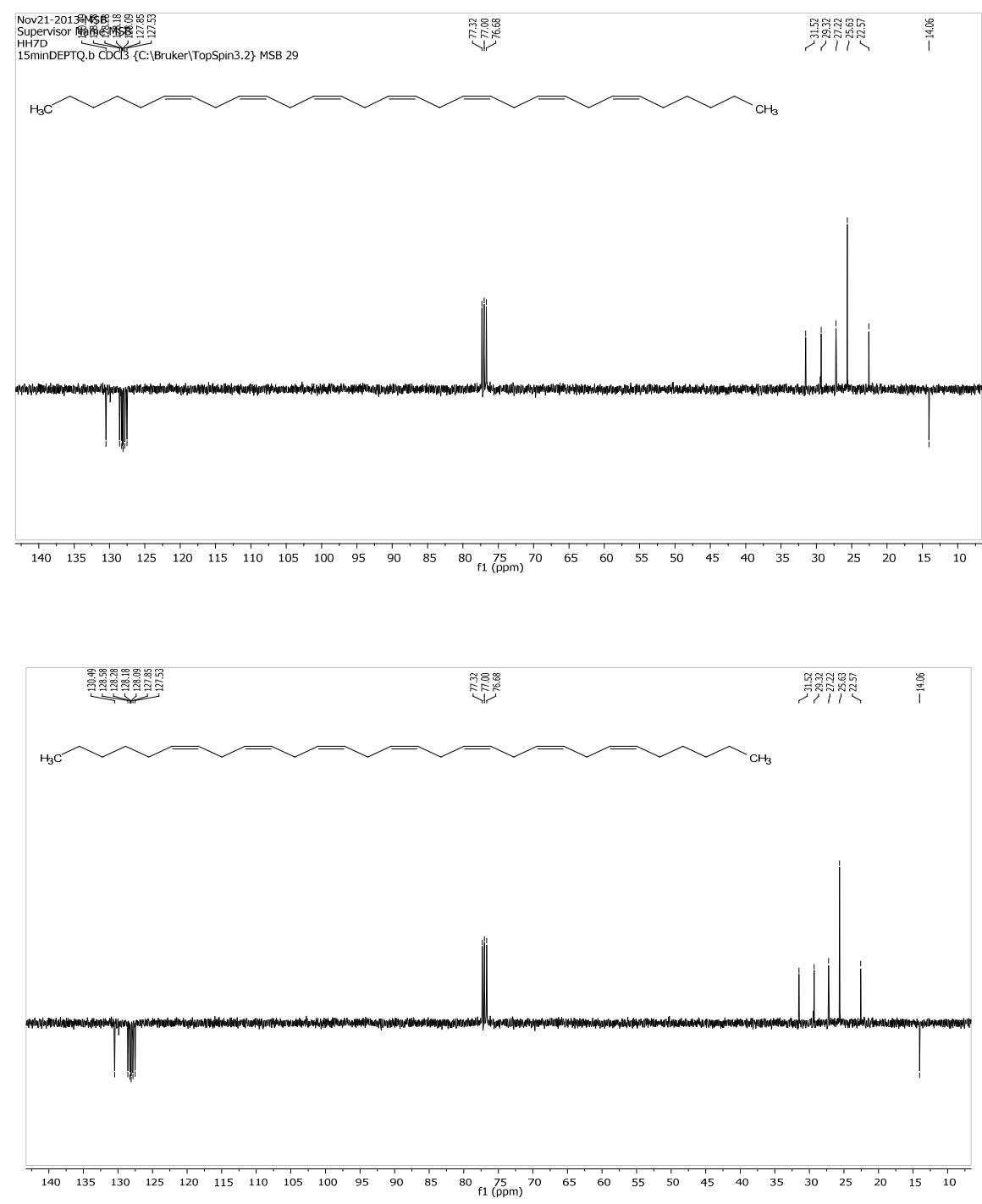

Dept-CNMR of compound (4) $\mathrm{CDCl}_{3}$ 
Int.J.Curr.Microbiol.App.Sci (2016) 5(1): 498-513

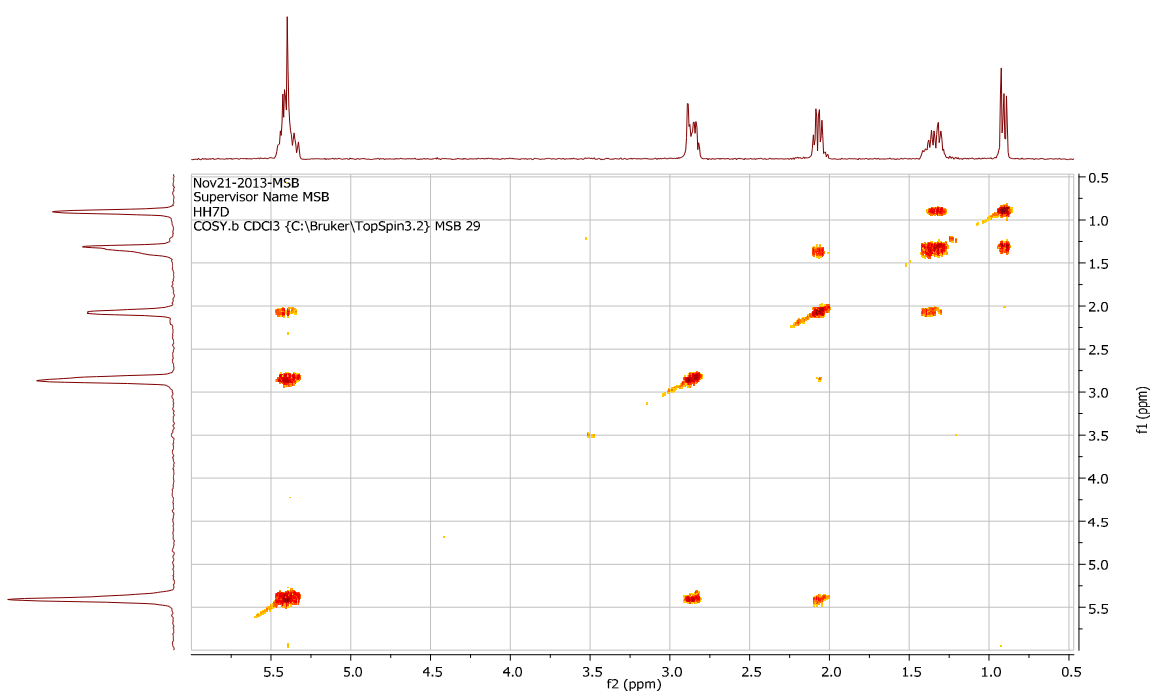

COSY NMR of compound (4) $\mathrm{CDCl}_{3}$

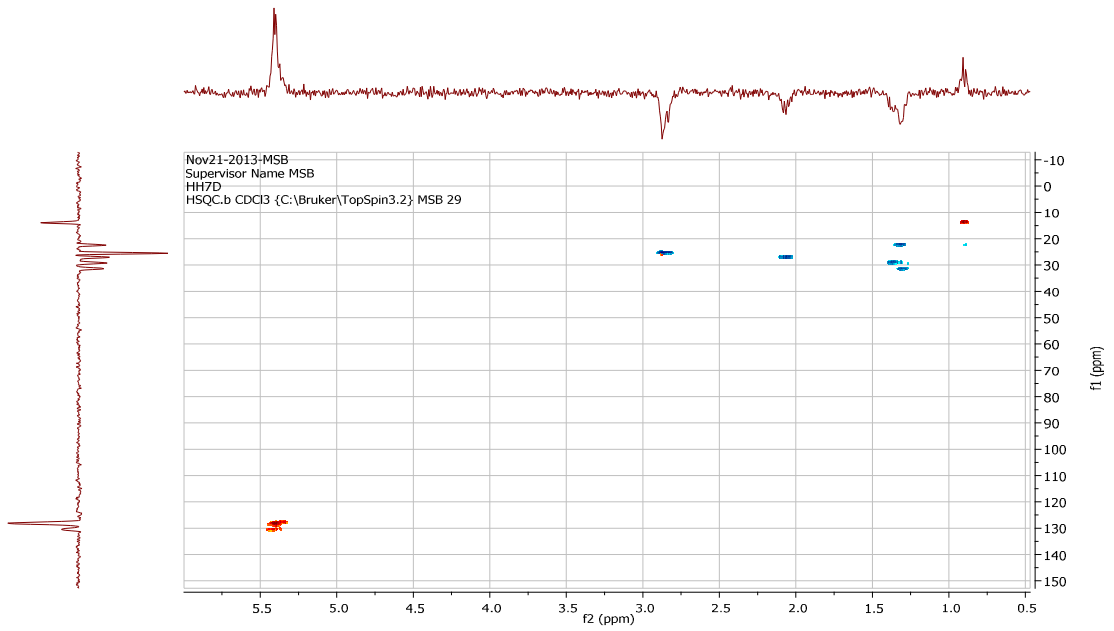

HSQC NMR of compound (4) $\mathrm{CDCl}_{3}$

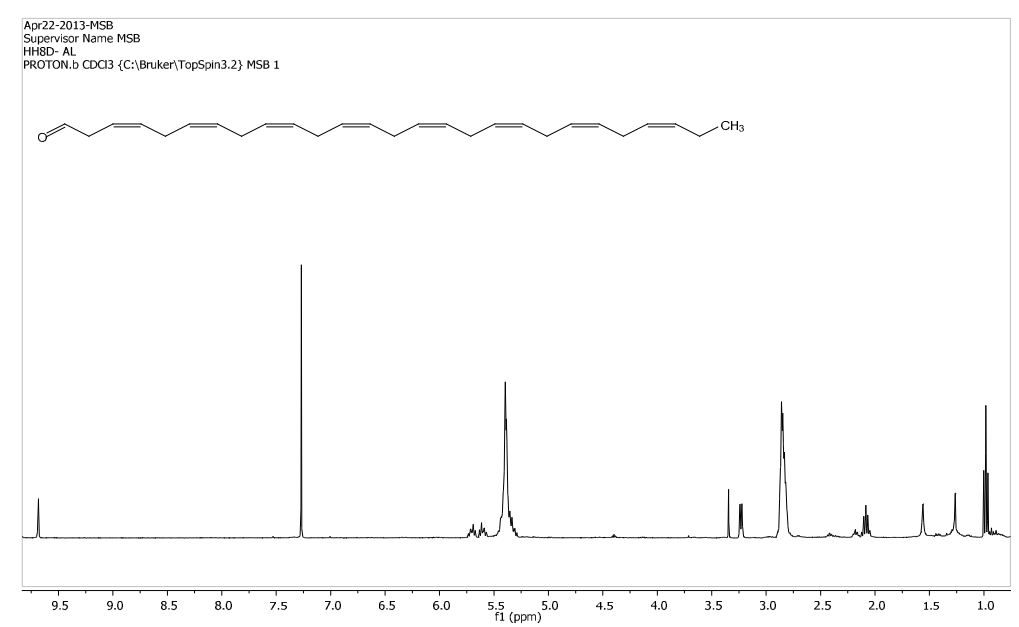


Int.J.Curr.Microbiol.App.Sci (2016) 5(1): 498-513

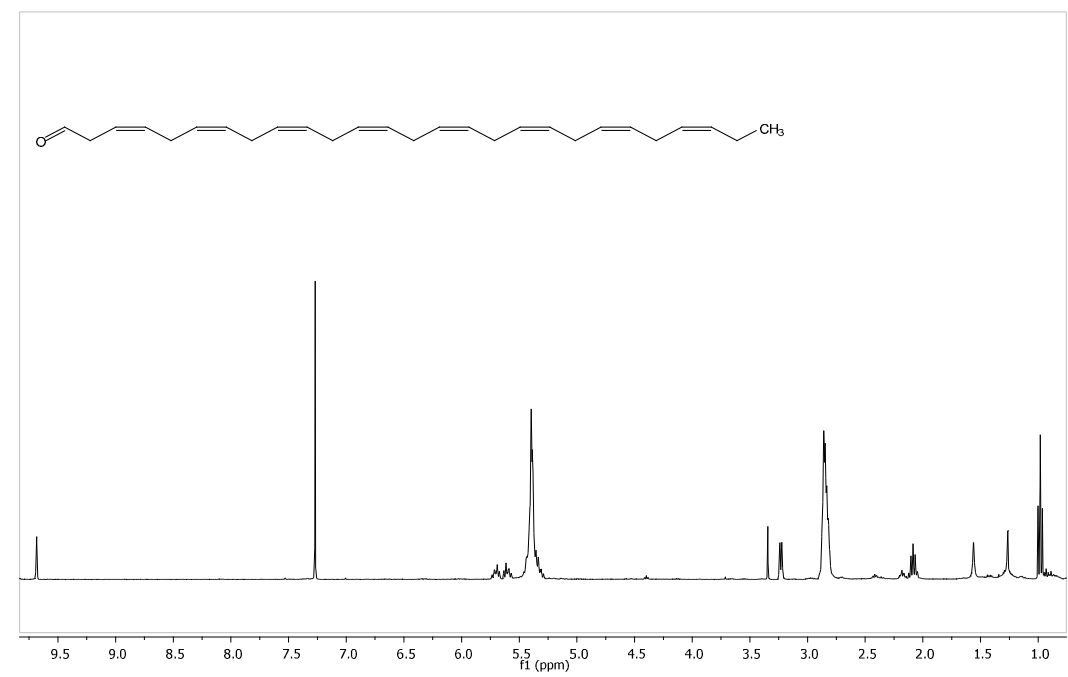

${ }^{1} \mathrm{H}$ NMR of compound (6) in $\mathrm{CDCl}_{3}$
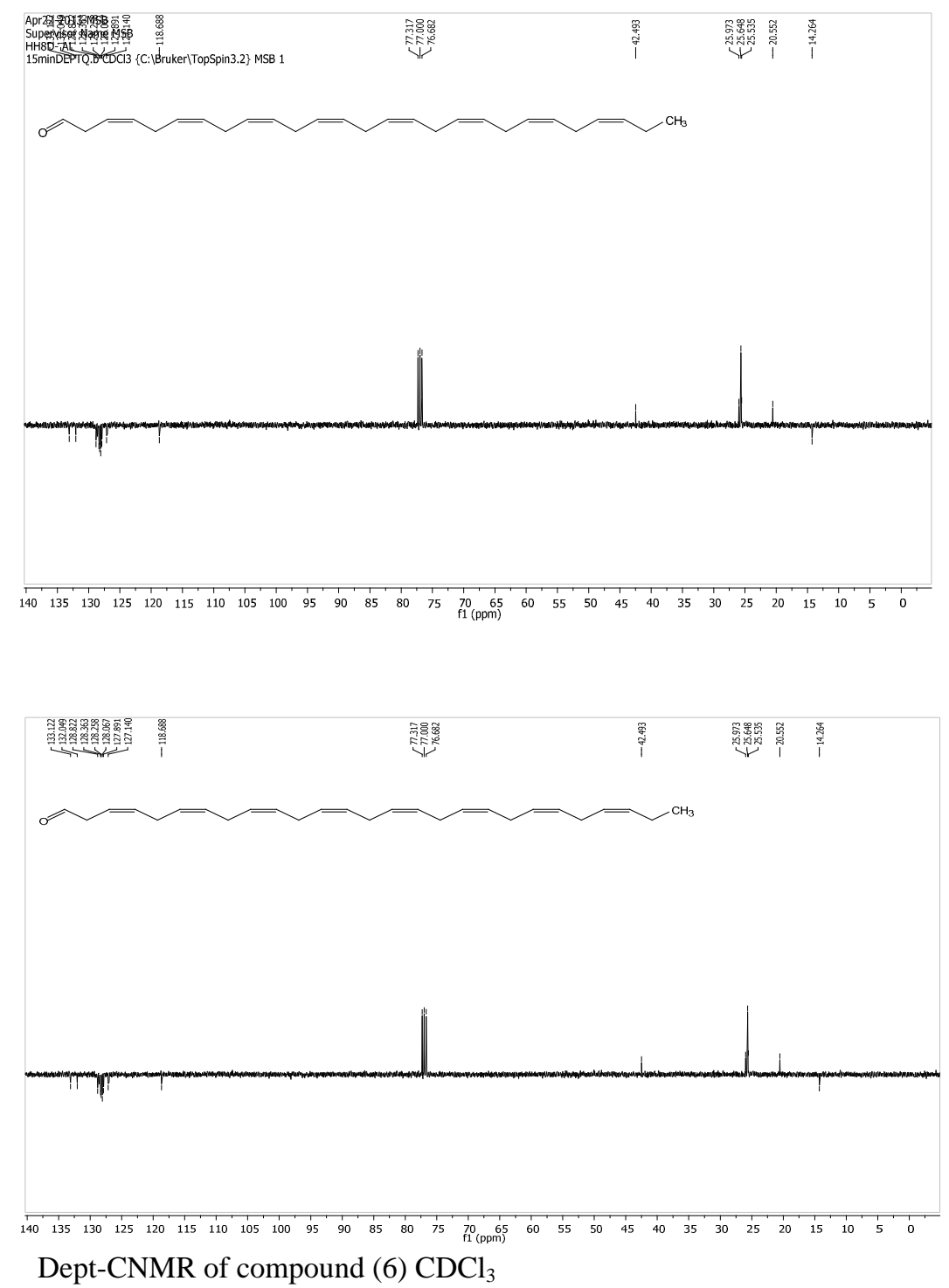


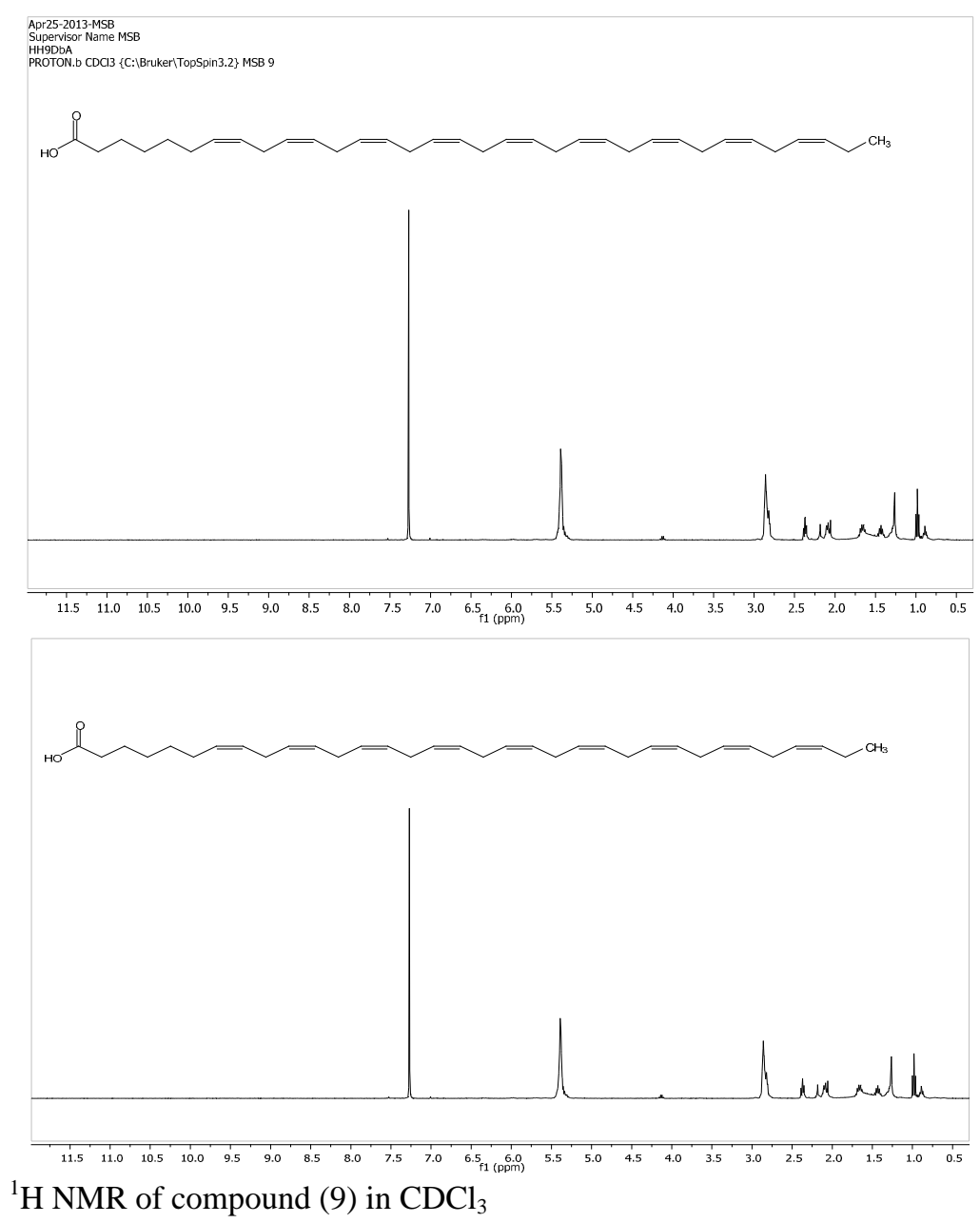

The ${ }^{13} \mathrm{C}$ NMR spectrum showed the required number of resonances, including the carbonyl carbon signal at $\delta 179.5$, with the alkene carbons resonating between $\delta 132$ and $127 \mathrm{ppm}$, and with signals occurring at $\delta$ $33.8,28.9,26.8,25.6,25.5,24.2,20.5$ respectively and finally a signal at 14.2 for the carbons of the terminal methyl groups. The IR spectrum included a broad peak at $3444 \mathrm{~cm}^{-1}$ for the $\mathrm{OH}$ stretch and a peak at $1709 \mathrm{~cm}^{-1}$ for the $\mathrm{C}=\mathrm{O}$ stretch.

However, the Wittig reaction was used to prepare several useful compounds with by extending the eightene motif of (6) by $\mathrm{CH}_{3}\left(\mathrm{CH}_{2}\right) \mathrm{n}$ when $\mathrm{n}=1,2,3$ and 4 carbon atoms respectively, employing Wittig salts of different chain lengths in dry THF at low temperature, in the presence of sodium bis(trimethylsilyl)amide as a base, to give (10) the structures of which were confirmed by their mass spectra and the NMR spectra, and IR. Similar data approximately had been obtained when the $(3 \mathrm{Z}, 6 \mathrm{Z}, 9 \mathrm{Z}, 12 \mathrm{Z}, 15 \mathrm{Z}$, 18Z,21Z,24Z,27Z)-pentatriaconta-3,6,9,12, $15,18,21,24,27$-nonaene (10) was prepared, except the aldehyde signal had disappeared while a new signal appeared corresponding to the second terminal methylene group, With the appearance of new signals belonging to the series methylene groups and some shifting for the signals which close to the function groups as mention in experimental data.

In conclusion, controlled wittig reaction conditions between phosphonioum salt and an pentaene aldehydes which formed from 
unsaturated acetal and diacetal leads to the formation unsaturated alkenes compounds with Z-double bonds configuration. These products could widely be used in the synthesis of insect pheromones instead of insecticides, fatty acid and may also be as useful intermediate compounds in many chemical reactions.

\section{Acknowledgement}

The authors acknowledge the thorough revision of Dr. Yahya Jirjees Salman, Department of Basic Sciences, College of Dentistry, University of Kerkuk, also I grateful to my supervisor in Ph.D. study Professor Mark S. Baird, a. School of Chemistry, Bangor University, Bangor, Gwynedd, LL57 2EZ.

\section{References}

1.Green, R. H.; Lamberts, P.F.; Tetrahedron, 1983, 39, 1687-1695.

2.Kremer, J.M.; Lawrence, D.A.; Sherman, M.; Arthritis and Rheumatism, 1990, 33, 810817.

3.Kher, V.; Barcelli, U.; Pollak, V.E.; Prostaglandins Leukotrienes Med. 1986, 22, 323-332.

4.Das, U.N; Nutrition, 1990, 6, 429-442.

5.Simopoulos; A. P.; DC 20009, The Center for Genetics, Nutrition and Health, Washington, 674-688

6.Simopoulos, A.P.; 2006, Biomedicine \& Pharmacotherapy 60, 502-507.

7.Mori, K.; 2005, Organic synthesis in pheromone science. Molecules10, 10231047.

8.Mori, K.; Tashiro, T.; 2004, Useful reactions in modern pheromone synthesis, Current Organic Synthesis, 1, 11-29.
9.Flock, S.; Lundquist, M.; L., Skattebol; 1999, Syntheses of some polyunsaturated sulfurand oxygen-containing fatty acids related to eicosapentaenoic and docosahexaenoic acids. Acta Chem. Scand. 53, 436-445.

10.Baba, N.; Alam, M.K.; Mori, Y.; S.S., Haider, M., Tanaka, S., Nakajima, S., Shimizu; 2001, A first synthesis of a phosphatidylcholine bearing docosahexaenoic and tetraco sahexaenoic acids. J. Chem. Soc., Perkin Trans. I, 221223

11.Itoh, T.; Tomiyasu, A.; Yamamoto, K.; 2011, Efficient Synthesis of the Very-LongChain n-3 Fatty Acids, Tetracosahexaenoic Acid (C24:6n-3) and Tricosahexaenoic Acid (C23:6n-3). Lipids 46, 455-461.

12.Michaud, S.; Viala, J.; 1999, Tetrahedron, 55, 3019-3024.

13.Flock, S.; Lundquist, M.; L.; 1999, Skattebol, Acta Chem. Scand., 53, 436-445.

14.Hussein, H. M.; Mark S. B.; Dulayymi, J. R.; Slava T.; 2014, A nine carbon homologating system for skip-conjugated polyenes, Chemistry and Physics of Lipids, 183, 34-42.

15.Westman, G.; Wennerström, O.; Raston, I.; 1993, Tetrahedron, 49, 483-488.

16.Clayden, J.; Greeves, N.; Warren, S.; Wothers, J.; 2004, Organic Chemistry, Oxford University Press.

17.Maryanoff , B. E.; Reitz, A. B.; 1989, Chem. Rev., 89, 863-927.

18.Anderson, R. J.; Henrick, C. A.; 1975, J. Am. Chem. Soc., 97, 4327-4334.

19.Reitz, A. B.; Nortey, S. O.; Jordan, A. D.; Mutter, M. S.; Maryanoff, B. E.; 1986, J. Org. Chem., 51, 3302-3308.

20.Maryanoff, B. E., Reitz, A. B.; DuhlEmswiler, B.; J. Am. Chem. Soc., 1985, 107, 217-226.

\section{How to cite this article:}

Hussein Habeeb Mustafa. 2016. Synthesis of a Novel Unsaturated Polyolefin Intermediates, Aldehyde and Fatty Acid. Int.J.Curr.Microbiol.App.Sci. 5(1): 498-513 ihttp://dx.doi.org/10.20546/ijcmas.2016.501.050 